\title{
Improved Automotive Fuel Resistance of Natural Rubber/Chlorosulfonated Polyethylene Blends by Blending Epoxidized Natural Polymer
}

\author{
Manisara Phiriyawirut, Sawanya Luamlam \\ Department of Tool and Materials Engineering, King Mongkut's University of Technology Thonburi, Bangkok, Thailand \\ Email: manisara.pee@kmutt.ac.th
}

Received July 9, 2013; revised August 9, 2013; accepted August 16, 2013

Copyright @ 2013 Manisara Phiriyawirut, Sawanya Luamlam. This is an open access article distributed under the Creative Commons Attribution License, which permits unrestricted use, distribution, and reproduction in any medium, provided the original work is properly cited.

\begin{abstract}
The natural rubber (NR) was mixed with chlorosulfonated polyethylene (CSM), due to the difference of polarity in NR and CSM made this blend incompatible and the third component was used. Epoxidzed natural rubber (ENR) was used as a third component. NR/CSM blended with the blend ratio of 50/50 was prepared by using a two-roll mill and vulcanization in a compression mold at $160^{\circ} \mathrm{C}$. The ENR content was varied from 1 to 7 phr. The curing characteristics, morphology, mechanical properties, and automotive fuel swelling were investigated. The results indicated that the cure time of the blend rubbers was shorter as adding ENR. The mechanical properties of the blend rubbers were not affected by ENR content. However, automotive fuel resistance of the blend rubbers was found to increase with adding ENR in rubber blend.
\end{abstract}

Keywords: Natural Rubber; CSM Rubber; Blend; Epoxidized Natural Rubber; Automotive Fuel Resistance

\section{Introduction}

Natural rubber (NR) is deteriorated by ozone and thermal attack due to a highly unsaturated backbone, and it also shows low oil and chemical resistance due to nonpolarity [1]. This is the drawback of NR for use as the products in automotive system especially for contact automotive fuel. Elastomeric blends are frequently used in the rubber industry to obtain best compromise in compound physical properties, processability and cost [2]. Blending NR with other high oil resistance rubber has been reported in many articles such as blending with chloroprene rubber [3], ethylene-propylene-diene rubber [4], dichlorocarbene modified styrene butadiene rubber [5], or hydrogenated nitrile rubber [6].

Chlorosulfonated polyethylene (CSM) is a special purpose elastomer because of its ideal balance of properties such as ozone, oxygen, weather, heat, oil, and chemicals resistance with good mechanical properties. Owing to the presence of the polarity of the chlorine group in CSM, NR/CSM blends should be resistant to ozone, oil, heat, flame, and nonpolar chemicals. Based on chemical structure, the NR/CSM blend may result in materials with inferior mechanical properties owing to the incom- patibility arising from the difference in polarity $[7,8]$. This result was the same as blended NR with higher polarity such as fluoro elastomer [9]. The difference in polarity of the rubbers causes high interfacial, which is detrimental. It will severely limit mixing at the interface, and hence the opportunity for crosslinking between the rubbers. It also causes poor phase morphology, which is characterized by large phase sizes.

These problem can be mitigated to an extent by the use of suitable modifiers that minimize the phase separation and increase interfacial adhesion; these include the addition of physical or chemical compatibilizers [10,11], (the addition of a third homopolymer or graft or block copolymer) that bind with the two phases and introduce the covalent bonds between the homopolymer phases. The compatibilizer also reduces the interfacial tension that is responsible for phase separation. According to C. Sirisinha et al. [12], the addition of maleated ethylene propylene diene rubber (EPDM-g-MA) reduced phase sized and increased oil and thermal aging of chlorinated polyethylene/natural rubber blend. H. Ismail and H. M. Hairunezam [13] studied compatibility problems in compatible styrene butadiene rubber/epoxidized natural rubber blends. Styrene-(epoxidized butadiene)-styrene tri- 
block copolymer (ESBS) was reported to act as compatibilizer for these blends.

Epoxidized natural rubber (ENR) contains polyisoprene as main chain and epoxidize group as side group which should be reacted to NR and CSM molecules, respectively. Then, ENR was interested to be used as a third component for NR/CSM blend. Figure 1 shows the chemical structure of NR, CSM and ENR, respectively.

Based on the above considerations, the main objective of this contribution paper was to improve automotive fuel resistance of NR/CSM blend by adding ENR. The selected automotive fuels were B5-biodiesel, diesel, gasoline and gasohol. Curing characteristics, morphology, and mechanical properties of rubber blend were also studied.

\section{Experimental}

\subsection{Materials}

The natural rubber used in this study was STR5L, produced in Thailand. Chlorosulfonated polyethylene, (Hypalon ${ }^{\circledR} 40$ ) was supplied by DuPont. Epoxidized natural rubber with 25\% epoxidizing group (ENR-25) was donated by Muang Mai Guthrie Public Co., Ltd. Thailand. All chemicals for rubber compounding were commercial grade obtained from local rubber chemical suppliers. The selected automotive fuels in this experiment were gasoline, gasohol, diesel and B5-biodiesel which supplied from petroleum station of PTT Public Co., Ltd., Thailand. The gasohol is $10 \%$ of ethanol blended with conventional gasoline and B5-biodiesel is 5\% of biodiesel blended with conventional diesel.

\subsection{Mixing and Vulcanization Procedure}

The compound composition of the rubber blend was given in Table 1. Mixing of NR, CSM, ENR and all chemicals were carried out on a laboratory size two-roll mill at room temperature. To vulcanize the blends, the compounds were then compression molded using a hydraulic hot press at $160^{\circ} \mathrm{C}$ under pressure $15 \mathrm{MPa}$ according to the respective cure times determined by oscillating disk rheometer machine (ODR GT-707052). The ODR gives digitals outputs of curing characteristics such as scorch

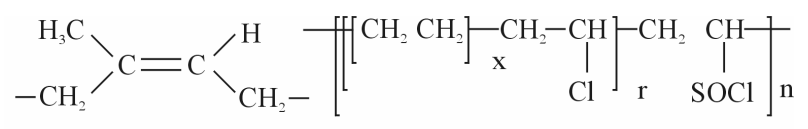

Natural rubber, NR Chlorosulfonated polyethylene, CSM<smiles>CC/C=C(\C)CCC1OC1(C)CC</smiles>

Epoxidizednaturalrubber, ENR

Figure 1. Chemical structure of investigated polymers.
Table 1. The compound composition of NR/CSM blends with and without ENR.

\begin{tabular}{cc}
\hline Ingredients & ${\text { Content }(\mathrm{phr})^{\mathrm{a}}}^{\mathrm{N}}$ \\
\hline NR (STR 5L) & 50 \\
CSM & 50 \\
ENR-25 & $0-7$ \\
Sulfur & 2 \\
6PPD & 4 \\
MgO $^{\mathrm{b}}$ & 5 \\
Stearic acid & 2 \\
TMTD $^{\mathrm{c}}$ & 1
\end{tabular}

a phr, parts per hundred; ${ }^{\mathrm{b}} 6 \mathrm{PPD}, N$-(1,3-dimethylbutyl)- $N$-phenyl-p-phenylenediamine; ${ }^{\mathrm{c}}$ TMTD, Tetramethyl thiuram disulfide.

time, cure times and torque value.

\subsection{Testing}

Morphological test: Morphological study was carried out using the Philips, XL30CP scanning electron microscope with $20 \mathrm{kV}$ accelerating voltage with complementary surface preparation techniques via $\mathrm{OsO}_{4}$ staining to improve the phase contrast. Each sample was sputtered with a thin layer of gold prior to SEM observation.

Mechanical tests: Dumbbell shaped tensile specimen and angel die shape tear specimen were punched form the compression-molded slap along the mill grain direction using an ASTM standard die. The mechanical tests were carried out per the ASTM D412 and ASTM D1004 for tensile test and tear test, respectively. The Instron 2532 tensile tester and LLOYD tear resistance tester were both examining at a crosshead speed of $500 \mathrm{~mm} /$ min with load cell of $500 \mathrm{~N}$.

Automotive fuel resistance tests: The automotive fuel resistance tests were carried out per the ASTM D471. Square test specimens of $2 \times 2 \times 2 \mathrm{~cm}^{3}$ were weighed accurately before immersing into automotive fuel at 25 and $70^{\circ} \mathrm{C}$. After a specific time of swelling, the specimen was removed from the fuel and weighed again after removing surface fluids by blotting with filter paper. The percentage of swelling was calculated according to the Equation (1)

$$
\% \text { swelling }=\frac{\mathrm{W}_{2}-\mathrm{W}_{1}}{\mathrm{~W}_{1}} \times 100
$$

where $W_{1}$ and $W_{2}$ represent the weight of the specimens after and prior to immersion into automotive fuel.

\section{Results and Discussion}

\subsection{Cure Characteristic}

The effect of ENR content on cure characteristic of 50/50 
$\mathrm{NR} / \mathrm{CSM}$ blend at $160^{\circ} \mathrm{C}$ was investigated by ODR. The cure characteristics of NR/CSM blends i.e., scorch time, cure time and different in torque values of NR/CSM rubber blends specimen before and after curing (MH-ML) were shown in Figure 2.

Scorch time is the time taken for the minimum torque value to increase by two units. It is a measure of premature vulcanization of the material. The scorch times of blends were found no significantly changed by increasing ENR content. While, the cure time of the blends were found to deceased by adding of ENR but not significantly change with increasing ENR content. The shorter cure time of the NR/CSM with ENR was due to the presence of ENR which catalyzed the crosslink reaction. The mechanism of reaction between ENR and CSM was proposed by Antony and coworkers [14]. The crosslink reaction between CSM and ENR in the blend was confirmed by FT-IR result which showed the absence of $\mathrm{SO}_{2}$ symmetric and the presence of new bands of $\mathrm{SO}_{2}$ symmetric stretching vibration in sulfonates. Work related to the ENR/chlorinated polyurethane blend was also studied by Mukhopadhyay and De [15]. The blend was designated as a self-crosslinkable system. The mechanism of cross-

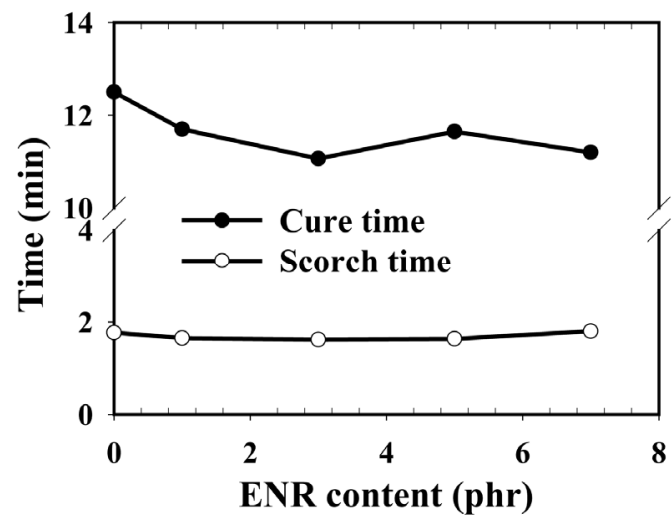

(a)

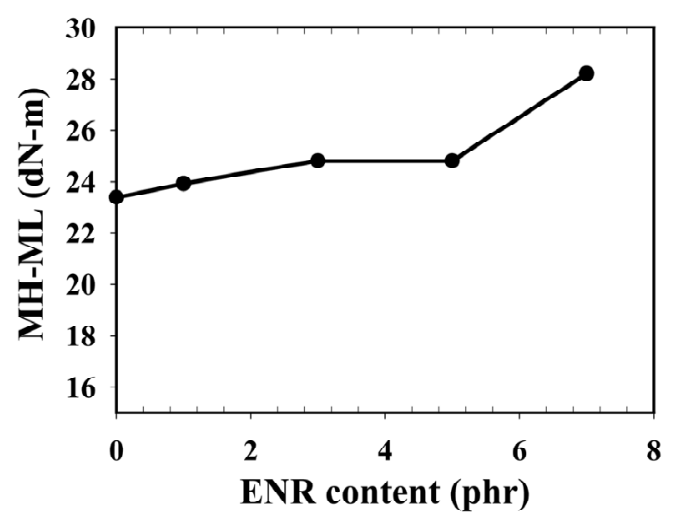

(b)

Figure 2. Cure characteristics of NR/CSM blends with different ENR content (a) cure time and scorch time and (b) different torque values (MH-ML). link reaction between the $\mathrm{SO}_{2} \mathrm{Cl}$ group of CSM and the epoxy group of ENR forming sulfonate type of linkage was proposed.

NR/CSM blending without ENR has low MH-ML value due to less interaction between NR and CSM molecules. The addition of ENR to the blend was progressively increasing the MH-ML value and it was gradually increased by increasing ENR content from 5 to $7 \mathrm{phr}$. The increasing of ODR torque is the effect on increasing of crosslinking density which results form more content of ENR which can catalyst the crosslink reaction.

\subsection{Morphological Properties}

The different of viscosity value between NR and CSM before blending were affecting to the miscibility of the blend. The higher difference value resulted in difficult to miscible blend. In this study, NR was Mooney viscosity (ML $\left.(1+4) 100^{\circ} \mathrm{C}\right)$ of 79.3 while, CSM was 63. Thus 50/50 NR/CSM blend became immiscible blend.

The SEM micrographs of the fracture surfaces of NR/ CSM blend were shown in Figure 3. It was found that the fracture surfaces showed higher surface roughness of the NR/CSM blend with ENR when compared with the blend without ENR. The fracture surface of the NR/CSM

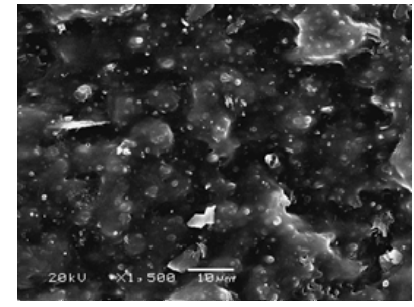

(a)

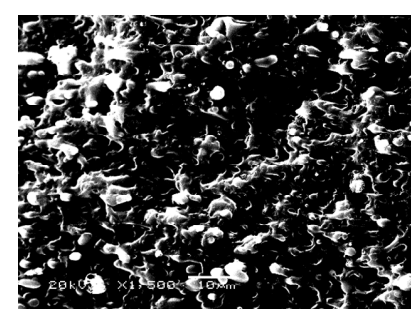

(c)

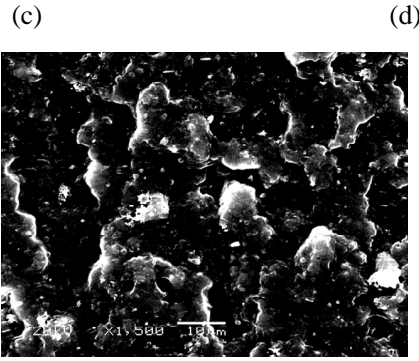

(e)

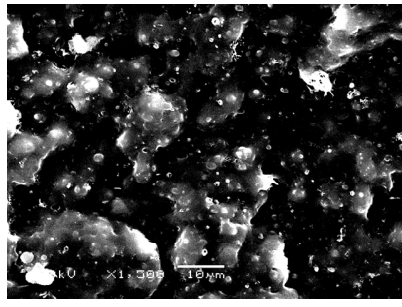

(b)

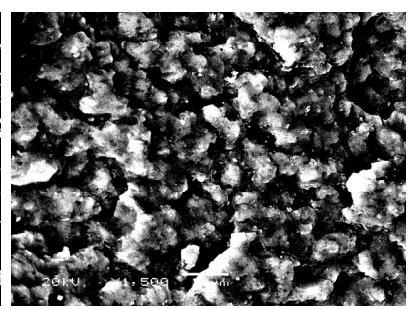

(d)
Figure 3. Scanning electron micrograph of fracture surface NR/CSM blend with different ENR content (a) 0 phr (b) 1 phr (c) 3 phr (d) 5 phr and (e) 7 phr. 
blend without ENR showed the immiscible blend morphology. The improved interfacial adhesion in case of the compatiblized blend rendered the surrounding matrix to be tightly held by the elastomer domains during fracture, which caused the texture of the fracture surface to loose its flatness owing to three-dimensional distribution of dispersed domains. However, for different ENR content, the morphology was seem to not significantly different.

\subsection{Mechanical Properties}

The mechanical properties, in terms of tensile strength, modulus at $100 \%$ and $300 \%$ elongation, elongation at break, tear strength and hardness were determined for NR, CSM and a series of NR/CSM rubber blends with and without ENR component and the results were listed in Table 2.

For pure cured CSM exhibited a much stronger characteristic than pure cured NR. Thus 50/50 NR/FKM blends without ENR component, it was found that the rubber blends were quite stronger than NR. However, the mechanical properties of the blend were not good enough because of lacking of interaction between NR and CSM molecule due to different in polarity of NR comparing to the CSM rubber.

The tensile properties of NR/CSM blends such as tensile strength and tensile modulus were found to be slightly increased by addition of ENR and but non-significantly affected by ENR content. Moreover, the addition ENR was slightly decreased elongation at break. It was shown that the tensile properties of the blend exhibited some extent of improvement with the addition of ENR. This was due to the achievement of interaction between ENR and CSM molecule. Furthermore, the higher strength and lower elasticity of the blend is due to high degree of crosslinking which confirmed by ODR results. The results were clearly in good agreement with the different torque values results.

In contrast, the tear strength of pure NR cured speci- men was found to be ca. $12.41 \mathrm{~N} / \mathrm{mm}$ while CSM cure specimen was $30.31 \mathrm{~N} / \mathrm{mm}$. For the rubber blend without ENR was 13.75 which closely to the value the pure NR specimen and addition ENR into the blend showed no effect on tear strength. This was due to insufficient epoxidized molecules to bond between NR and CSM molecules. This result was similar to previous report [7].

The hardness of pure NR cured specimen was found to be ca. 21 Shore A while CSM cure specimen was 53.8 Shore A. For the rubber blend without ENR was 37.2 Shore A which intermediated between the pure components. However, the hardness of NR/CSM blend was not effect by ENR addition and content of ENR.

\subsection{Automotive Fuel Resistance}

CSM is very well known for its excellent hydrocarbon fluids resistance characteristics. In the other hand, NR is non-polar rubber with low oil and solvent resistant behavior. NR/CSM blend was found to lower resistance to automotive fuel due to the lack of interaction between NR and CSM phase leading to the weakest point at interphase and resulted to high penetrated of fuel into rubber blend.

The effect of ENR content of NR/CSM blend on automotive fuel was investigated by determined the percentages of swelling. The swelling temperature with 25 and $70^{\circ} \mathrm{C}$ was also investigated. The percentages of swelling of a series of NR/CSM blends with different ENR content were shown in Figure 4 as a function of immersion time in selected automotive fuels.

For effect of time and temperature, the percentages of swelling increased by increasing immersion time. The rate of swelling increased exponentially with time. Furthermore, the percentages of swelling of the blends were found to increase at high temperature due to the high temperature, rubber molecule had trend to easier motive. Then molecules of fuel were more penetrated into the rubber phase, result in increasing percentage of swelling.

Table 2. Mechanical properties of NR, CSM and NR/CSM blends.

\begin{tabular}{|c|c|c|c|c|c|c|}
\hline \multirow{2}{*}{ Rubber sample } & \multicolumn{6}{|c|}{ Mechanical properties } \\
\hline & $\begin{array}{l}\text { Tensile strength } \\
\text { (MPa) }\end{array}$ & $\begin{array}{l}\text { 100\% Modulus } \\
(\mathrm{MPa})\end{array}$ & $\begin{array}{l}\text { 300\% modulus } \\
(\mathrm{MPa})\end{array}$ & $\begin{array}{l}\text { Elongation at break } \\
\qquad(\%)\end{array}$ & $\begin{array}{l}\text { Tear strength } \\
\text { (N/mm) }\end{array}$ & $\begin{array}{l}\text { Hardness } \\
\text { (Shore D) }\end{array}$ \\
\hline NR & $3.79 \pm 0.32$ & $0.31 \pm 0.03$ & $0.55 \pm 0.05$ & $898 \pm 72$ & $12.41 \pm 0.81$ & $21.0 \pm 1.41$ \\
\hline NR/CSM + ENR 0 & $5.67 \pm 1.19$ & $0.61 \pm 0.05$ & $1.21 \pm 0.15$ & $555 \pm 76$ & $13.75 \pm 0.67$ & $37.2 \pm 1.72$ \\
\hline NR/CSM + ENR 3 & $6.84 \pm 0.68$ & $0.65 \pm 0.01$ & $1.30 \pm 0.06$ & $516 \pm 21$ & $11.42 \pm 0.75$ & $38.3 \pm 1.03$ \\
\hline NR/CSM + ENR 5 & $6.04 \pm 0.95$ & $0.63 \pm 0.01$ & $1.33 \pm 0.09$ & $493 \pm 12$ & $12.67 \pm 1.72$ & $37.7 \pm 1.03$ \\
\hline NR/CSM + ENR 7 & $8.25 \pm 0.63$ & $0.66 \pm 0.02$ & $1.53 \pm 0.31$ & $521 \pm 38$ & $13.31 \pm 1.87$ & $36.3 \pm 0.95$ \\
\hline CSM & $19.27 \pm 0.66$ & $1.22 \pm 0.03$ & $5.03 \pm 0.17$ & $413 \pm 34$ & $30.31 \pm 1.66$ & $53.8 \pm 1.18$ \\
\hline
\end{tabular}




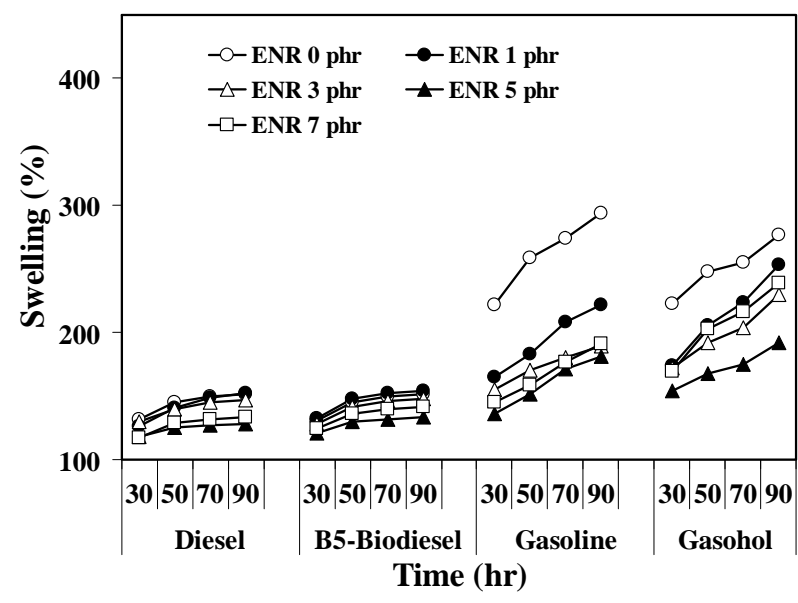

(a)

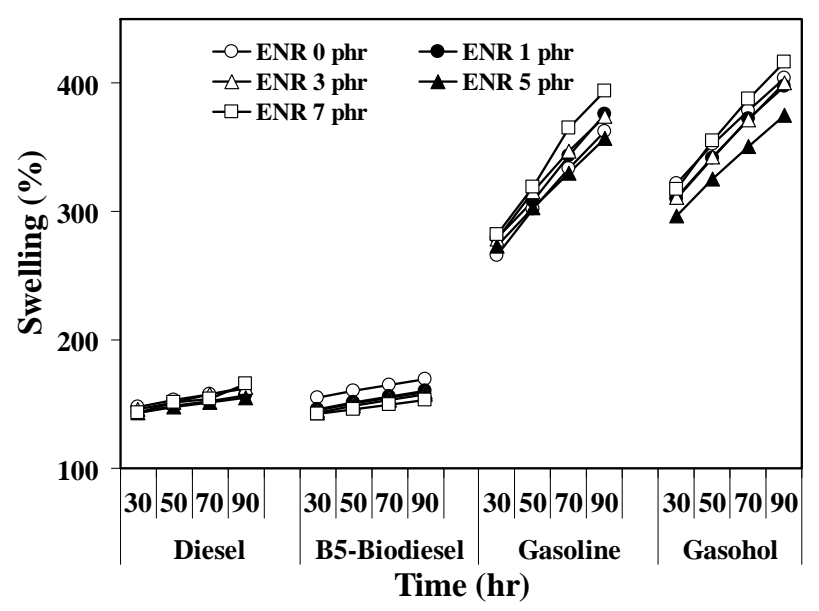

(b)

Figure 4. Percentage of swelling in selected automotive fuels of NR/CSM blend with different ENR contents for various immersion time at (a) $25^{\circ} \mathrm{C}$ and (b) $70^{\circ} \mathrm{C}$.

After interval of immersion time, it is interesting to note that the percentage of swelling of NR/CSM blend without ENR was greater than that of NR/CSM blend with ENR. For all selected automotive fuels, increasing ENR content, the percentage of swelling of NR/CSM blends was found to decrease, when ENR content is increased from 1 to $5 \mathrm{phr}$ but the percentage of swelling of NR/CSM blends was found to increase again, when ENR content is increased from 5 to $7 \mathrm{phr}$. The results show lowest swelling with adding 5 phr of ENR. The NR/CSM blend with high ENR content showed lower degree of swelling than those of the lower ENR content. Because of the improvement of interaction between NR and CSM by ENR molecule at enough ENR content.

In addition, ENR is a polar molecule, so increasing ENR in rubber blend was result in increasing polarity of the rubber blend. Consequently, ENR resisted the penetration of fuel molecules in to the rubber phases, thereby reducing the swelling. However as higher content of
ENR in this research, $7 \mathrm{phr}$, observed the higher degree of swelling due to the more NR phase in rubber blend. The usage ENR was 25\% epoxidizing group on NR molecules.

In term of type effect of automotive fuels, it was found that the percentage of swelling of NR/CSM blend with ENR in gasoline-based fuel was much greater than that in diesel-based fuel. Gasoline is predominantly a mixture of paraffins, naphthenes, and olefins, while diesel is composed of about $75 \%$ saturated hydrocarbons, and $25 \%$ aromatic hydrocarbons [16]. The diesel-based fuel was larger molecular size than those of gasoline-based fuels. The molecular size of fuel will reflect to the viscosity and penetration ability into rubber phase. Thus dieselbased fuels were penetrated in ENR added rubber sample difficultly than gasoline-based fuels do. However, for comparing in percentage of swelling of these rubber blends in gasoline-based fuel, gasoline and gasohol, it was found slight different. The results were also achieved in between diesel-based fuel, diesel and B5-biodiesel.

\section{Conclusion}

The effect of ENR adding content on automotive fuel resistance of blends of NR and CSM had been investigated. In addition, the curing behavior, morphology, mechanical properties of the blends were also studied. NR/CSM blend with blend ratio of 50/50 was prepared by using a two-roll mill and vulcanizes in a compression mold at $160^{\circ} \mathrm{C}$. The self-crosslink reaction between ENR and CSM has better cure time and automotive fuel resistance. It has been found that ENR could be used to improve automotive fuel in the blend system studied. The optimal concentration of ENR is 5 phr. Beyond this concentration, good mechanical properties and automotive fuel resistance were achieved.

\section{Acknowledgements}

The financial support from Thailand Research Fund (TRF) based on "Small Projects on Rubber Project, SPR 50 " is gratefully acknowledged. The authors would like to acknowledge the facility support from Department of Tool and Materials Engineering, Faculty of Engineering, King Mongkut's University of Technology Thonburi.

\section{REFERENCES}

[1] A. J. Tinker and K. P. Jones, "Blends of Natural Rubber: Novel Techniques for blending with Speciality Polymers," Chapman \& Hall, London, 1998. http://dx.doi.org/10.1007/978-94-011-4922-8

[2] C. Koning, M. van Duin, C. Pagnoulle and R. Jerome, "Strategies for Compatibilization of Polymer Blends," Progress in Polymer Science, Vol. 23, No. 4, 1998, pp. 707-757. 
http://dx.doi.org/10.1016/S0079-6700(97)00054-3

[3] K. Saguan, T. Suteewong, P. Saendee, U. Buranabunya and P. Tangboriboonrat, "Composite Natural Rubber Based Latex Particles: A Novel Approach,” Polymer, Vol. 46, No. 4, 2005, pp. 1373-1378. http://dx.doi.org/10.1016/j.polymer.2004.11.074

[4] S. H. EL-Sabbagh, "Compatibility Study of Natural Rubber and Ethylene-Propylene-Diene Rubber Blends,” Journal of Applied Polymer Science, Vol. 90, No. 1, 2003, pp. 1-11. http://dx.doi.org/10.1002/app.12345

[5] M. T. Ramesan, "Thermogravimetric Analysis, Flammability and Oil Resistance Properties in Natural Rubber and Di-Chlorocarbene Modified Styrene Butadiene Rubber Blends,” Reactive and Functional Polymers, Vol. 59, No. 3, 2004, pp. 267-274.

http://dx.doi.org/10.1016/j.reactfunctpolym.2004.02.005

[6] K. I. Elizabeth, R. Alex and S. Varghese, "Evaluation of Blends of Natural Rubber and Hydrogenated Nitrile Rubber Containing Chemically Modified Natural Rubber," Plastics, Rubber and Composites, Vol. 37, 2008, pp. 359-366. http://dx.doi.org/10.1179/174328908X314343

[7] V. Tanrattanakul and A. Petchkaew, "Mechanical Properties and Blend Compatibility of Natural Rubber-Chlorosul-Fonated Polyethylene Blends," Journal of Applied Polymer Science, Vol. 99, No. 1, 2006, pp. 127-140. http://dx.doi.org/10.1002/app.22500

[8] G. Markovic, B. Radovanovic, J. Budinski Simendic and M. Marinovic-Cincovic, "Curing Characteristics of Chlorosulphonated Polyethylene and Natural Rubber Blends," Journal of Serbian Chemical Society, Vol. 70, No. 5, 2005, pp. 695-703. http://dx.doi.org/10.2298/JSC0505695M

[9] M. Phiriyawirut, "Preparation of Biodiesel Oil Resistance Rubbers from Natural Rubber/Fluoro Elastomer Blends,” Proceeding of the 2nd South East Asian Technical University Consortium (SEATUC) Symposium, Bandung, 2627 February 2008, pp. 50-55.

[10] A. Y. Coran and R. Patel, "Rubber-Thermoplastic Com- positions 1. EPDM-Polypropylene Thermoplastic Vulcanizates," Rubber Chemistry and Technology, Vol. 53, No. 1, 1980, pp. $141-150$. http://dx.doi.org/10.5254/1.3535023

[11] A. P. Plochocki, S. S. Dagli and R. D. Andrews, "Interface in Binary Mixtures of Polymers Containing a Corresponding Block Copolymer. Effects of Industrial Mixing Processes and of Coalescence,” Polymer Engineering and Science, Vol. 30, No. 12, 1990, pp. 741-752. http://dx.doi.org/10.1002/pen.760301207

[12] C. Sirisinha, P. Saeoui and J. Guaysomboon, “Oil and Thermal Aging Resistance in Compatibilized and Thermally Stabilized Chlorinated Polyethylene/Natural Rubber Blends,” Polymer, Vol. 45, No. 14, 2004, pp. 49094915. http://dx.doi.org/10.1016/j.polymer.2004.05.015

[13] H. Ismail and H. M Hairunezam, "The Effect of a Compatibilizer on Curing Characteristics, Mechanical Properties and Oil Resistance of Styrene Butadiene Rubber/ Epoxidized Natural Rubber Blends,” European Polymer Journal, Vol. 37, No. 1, 2001, pp. 39-44. http://dx.doi.org/10.1016/S0014-3057(00)00099-9

[14] P. Antony, S. K. De and M. van Duin, "Self-Crosslinking Rubber/Rubber and Rubber/Thermoplastic Blends: A Review,” Rubber Chemistry and Technology, Vol. 74, 2001, pp. 376-408.

[15] S. Mukhopadhyay and S. K. De, "Self-Vulcanizable Rubber Blend Systems Based on Epoxidized Natural Rubber and Chlorosulfonated Polyethylene: Effect of Blend Composition, Epoxy Content of Epoxidized Natural Rubber, and Reinforcing Black Filler on Physical Properties," Journal of Applied Polymer Science, Vol. 42, No. 10, 1991, pp. 2773-2786. http://dx.doi.org/10.1002/app.1991.070421016

[16] Agency for Toxic Substances and Disease Registry (ATSDR), “Toxicological Profile for Fuel Oils,” US Department of Health and Human Services, Public Health Service, 1995. 